PRODUCTION

ENGINEERING

ARCHIVES
2015, Vol. 7, No 2, pp 2-5

ISSN 2353-5156

ISSN 2353-7779 (print version)

(online version)

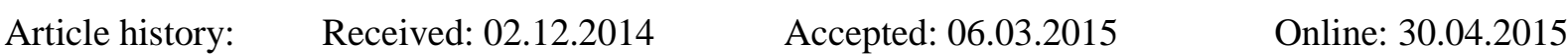

Available online on: http://www.qpij.pl

Exist since $4^{\text {rd }}$ quarter 2013

\title{
Development of polyurethane paint metallic effect without cloud defect
}

\author{
Lukasz Pasieczyński ${ }^{1}$, Norbert Radek ${ }^{2}$ \\ ${ }^{1}$ F. H. BARWA, ul. Warkocz 3-5, 25-253 Kielce, Poland, lpasieczynski@barwa.kielce.pl \\ ${ }^{2}$ Centre for Laser Technologies of Metals, University of Technology in Kielce, Al. 1000-lecia Państwa Polskiego 7, 25-314 Kielce, Poland, \\ norrad@tu.kielce.pl
}

\begin{abstract}
The article presents tests results of the metallic paint system. The system consists of high solid corrosion protection primer and dual-component topcoat with a metallic gloss effect (RAL 9006). The paint system properties were examined after the conditioning period. The measurements included an adhesion test, a flexibility test, hardness test, gloss test, a corrosion resistance test and a humidity resistance test. The article focuses on "cloud" defect in metallic paints because of grain distribution in topcoat and also presents results of the product developed in our company.
\end{abstract}

Key words - metallic effect, metallic pigment, cloud defect, topcoat defects

\section{Introduction}

In order to enhance the competitiveness of vehicle appearance and to attract customers, painting systems are used with special effects. One of them is the use of metallic pigments in paint topcoats. Such pigments glamorize the appearance of coatings, as well as create a protective barrier against harmful elements of the environment. The metallic effect is obtained by dispersing metallic aluminum (aluminum flakes, aluminum grain) in coating film. The process is difficult, because the final result of the achieved metallic coating is strongly dependent on many factors such as:

- pigment distribution and shape,

- surface smoothness,

- pigment orientation in relation to the surface of substrate or previous layer,

- pigment wettability,

- grain size.
Due to the shape, aluminum pigments are divided in two basic groups: irregular flakes (cornflakes Fig. 1) and lenticular flakes (silverdollar Fig. 2).

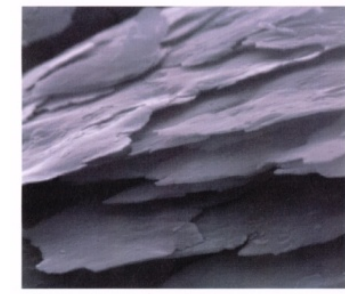

Fig. 1 Cornflakes. (http://www.schlenk.com)

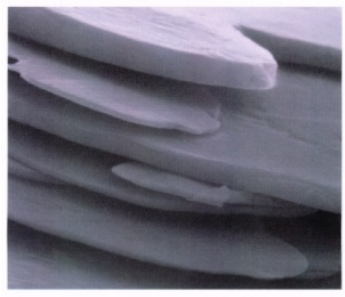

Fig. 2 Silverdollar. (http://www.schlenk.com)
The use of various shapes of metallic pigments causes differences in the gloss of coatings as well as their visual appearance (surface smoothness, the absence of protruding pigment). Irregular flakes (Fig. 1) will scatter the light more than the lenticular flakes 
(silverdollars) which have a more rounded shape (Fig. 2).

Lenticular flakes are commonly used in industrial and automotive paints. Another considerable factor is the size of particles dispersed in the system. The larger the particles are dispersed, the greater the metallic effect obtained (brilliant, sparkling effect). Smaller particles give a more homogenous effect with a darker coating because of the better light scattering at the edges of the particles (COLLECTIVE WORK 1983, HTTP://WWW.SCHLENK.COM).

As important as the shape of aluminum pigments is their distribution in a coating film: on the surface or in the entire volume of a resin. Every type of grain distribution has both its advantages and disadvantages. The way the grain is distributed in a resin depends on the technology of preparation. Leafing pigments of high surface tension do not get wetted by a resin and float onto the surface of a wet film. This effect is obtained by the use of stearic acid in the pigment production. However, in high polar systems, pigment may get wet from a resin and "drown" inside the coating, turning into a non-leafing pigment. The aaddition of oleic acid or dispersing agents in the production process causes such an effect. The metallic effect is obtained by light reflection on the smooth surface of aluminum flakes.

Reflected light may however, refract or scatter the flakes' edges or micro-roughness of the pigment surface. In that case the metallic effect is the sum of light reflection and scattering. The higher the ratio of reflected light, the greater and more intense the effect. The metallic effect depends on the grain distribution and therefore on the angle of reflection (SERVICE MANUAL 2008).

An important factor in the visual effect is pigment orientation of pigment in a coating film. The more parallel aluminum pigment flakes are arranged to the surface, the greater the light reflection. Poor orientation results in a cloudy appearance.

The type of grain and the process of its introduction into a metallic paint have an influence on the grain distribution in a resin and defects of coating appearance which may occur after application. Poor grain selection, its size and shape as well as improper mixing, lead to the atrophy of the metallic effect, the coating darkening or a "cloud" effect which is caused by improper pigment particle distribution. Cloud is formed by agglomeration of aluminum pigment particles in a resin and is observed by darker and brighter spots or stripes on the coating.

To avoid such defect on coating it is recommended to apply more paint layers and cross painting because each following paint layer reduces the cloud effect. However, it does increase production costs.

\section{Methodology of research}

The paint system design includes epoxy primer with high solid content and two-component polyurethane paint with a high metallic gloss effect. Epoxy provides very good adhesion to steel due to the multitude of functional groups in the polymer molecule and corrosion resistance. The topcoat paint RAL 9006 is designed by F.H. Barwa laboratory. The coating was applied with SATA spray guns with 1,3-1,4 nozzle on steel. Before the application the surface of steel was polished with 240-grit sandpaper. Next the epoxy primer was applied and heated at $60^{\circ}$ Celsius for $60 \mathrm{~min}$. The two layers of topcoat paint was applied wet-onwet with good concealing power. There was a $10 \mathrm{mi}-$ nute break between painting the two layers in order to evaporate thinners from coating. The samples were conditioned at 23 degrees Celsius and 50\% humidity for a minimum of 7 days in order to perform tests on a dry coating (HRYNIEWICZ T. 2004).

\section{Results and discussions}

The paint is easy applicable. It can be applied as simply as ordinary polyurethane topcoat without the necessity of cross painting or spraying to minimize the cloud defect. Additionally, RAL 9006 topcoat has a much thicker grain and its metallic effect is similar to a base coat system. This paint system also enables repair of a damaged paint surface by external factors (e.g. brushing, scratching) with low production costs and within a short time. As proof, a part of the sample was polished with P400-grit sandpaper and polyurethane coating was re-applied to the abrasion place. No defects were observed in the coating.

The metallic effect depends on many factors and each factor has a direct effect on the final coating. For this reason metallic effect measurement requires sever- 
al techniques: tint and color saturation, gloss, brightness, hiding power or DOI (distinctiveness of image).

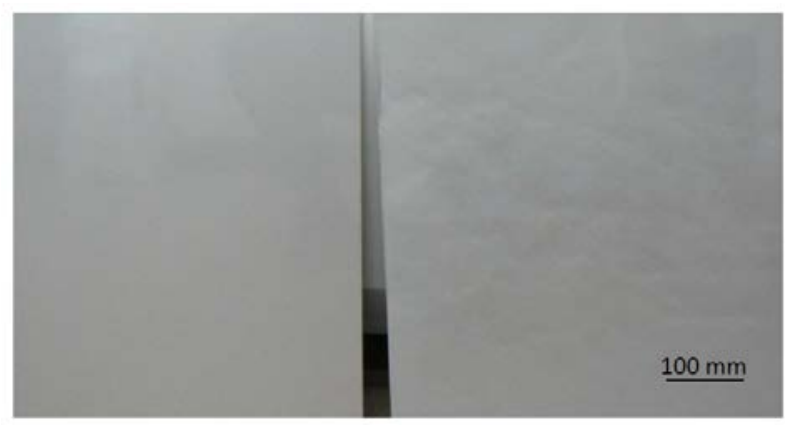

Fig. 3. Cloud defect on coating.

It causes an improvement in gloss, brightness and color saturation. Another measured parameter is a flop. It is a change in brightness, depending on the observation angle. It is especially noticeable on the car mask and bumper.

The DOI parameter is responsible for clarity of reflecting objects that surround the coating (trees, buildings, other cars).

There is a high demand on the market for paint coatings with a metallic effect. They should be high gloss, bright with visible metallic effect and have high DOI and flop co-efficient at the same time.

After the formulation the properties of the product were examined. Table 1 shows the results of the following tests performed on the liquid paint: density, solid content, flow time and drying time.

The values given in Table 1 were obtained on ready to use products (with added hardener and thinner).

Table 1. Properties of liquid product ready to use

\begin{tabular}{|l|l|l|}
\hline Test & Standard & Result \\
\hline Density $\left[\mathrm{g} / \mathrm{cm}^{3}\right.$ ] & PN-EN ISO 2811-1 & 0,95 \\
\hline Solid content by mass [\%] & PN-EN ISO 3251 & 57 \\
\hline $\begin{array}{l}\text { Solid content by volume [\%] } \\
\text { (calculation method) }\end{array}$ & $\begin{array}{l}\text { Technical procedu- } \\
\text { re }\end{array}$ & 54 \\
\hline Flow time cup Ford4 [sek.] & PN-EN ISO 2431 & 26 \\
\hline Drying time at $60^{\circ} \mathrm{C}[\mathrm{h}]$ & - & 2 \\
\hline Color RAL & - & 9006 \\
\hline
\end{tabular}

Cured coating was also tested for mechanical properties, corrosion and humidity resistance. After the conditioning period had finished, the thickness of dry coating was tested by the magnetic induction method, adhesion tests were performed by cross cut method and finally, a pull-off test. The hardness of cured coat- ing was measured by Koenig pendulum. The corrosion resistance test was performed in the salt spray chamber according to PN-EN ISO 9227 at $35^{\circ} \mathrm{C}$ using 5\% saline solution. The tests in a humidity chamber were conducted according to PN-EN ISO 6270-2 with the following parameters of the chamber inside: humidity $100 \%$, temperature $40^{\circ} \mathrm{C}$. Summary tests results are presented in Table 2.

The next test of resistance to aggressive environmental conditions (corrosion and moisture) were finished and assessed after 1000 hours of exposure. The result revealed no changes in the tested coatings (no blistering, cracking, corrosion or thread-like corrosion). 1000 hours is a minimum for the coating to be resistant to environmental effects. However, this time could be extended when aluminum is used as a substrate instead of steel.

Table 2. Selected properties of dry coating applied on steel

\begin{tabular}{|c|c|c|c|}
\hline Test & Standard & \multicolumn{2}{|c|}{ Result } \\
\hline Thickness $[\mu \mathrm{m}]$ & PN-EN ISO 2808 & \multicolumn{2}{|c|}{121,9} \\
\hline Cross cut & PN-EN ISO 2409 & \multicolumn{2}{|c|}{ No change } \\
\hline Adhesion [MPa] & PN-EN ISO 4624 & \multicolumn{2}{|c|}{4,96} \\
\hline $\begin{array}{l}\text { Hardness, Koenig } \\
\text { pendulum [s] }\end{array}$ & PN-EN ISO 1522 & \multicolumn{2}{|c|}{105} \\
\hline $\begin{array}{l}\text { Corrosion resistance } \\
\text { test }[1000 \mathrm{~h}]\end{array}$ & PN-EN ISO 9227 & \multicolumn{2}{|c|}{ No change } \\
\hline $\begin{array}{l}\text { Humidity resistance test } \\
{[1000 \mathrm{~h}]}\end{array}$ & PN-EN ISO 6270-2 & \multicolumn{2}{|c|}{ No change } \\
\hline \multirow{3}{*}{ Gloss [gloss unit] } & \multirow{3}{*}{ PN-EN ISO 2813} & $20^{\circ}$ & 67,2 \\
\hline & & $60^{\circ}$ & 94,2 \\
\hline & & $85^{\circ}$ & 90,9 \\
\hline
\end{tabular}

The paint could be applied by a wet on wet method or on the surface of dry sanded primer. To obtain entire paint coverage two layers should be applied. Our product does not cause a cloud effect but creates uniform varnish layer on the element. During the evaporation of solvents we can observe the grain which spreads across the entire surface within the next two or three minutes. In the next test the two samples were prepared with and without cloud defect. Each sample had a grid with a similar surface area. The surface of the samples was examined by spectrophotometer (with six different angles $-15^{\circ}, 15^{\circ}, 25^{\circ} 45^{\circ}, 75^{\circ}, 110^{\circ}$ ) to determine the change of the color by measuring $\mathrm{L}^{*} \mathrm{a}{ }^{*} \mathrm{~b}^{*}$ parameter. The results are shown in Figures 4 and 5.

Figures 4 and 5 present a comparison of color difference $(\Delta E)$ for samples with and without cloud de- 
fect in the two of six selected angles $\left(25^{\circ}\right.$ and $\left.45^{\circ}\right)$. The sample with cloud defect has a significantly higher value of $\Delta \mathrm{E}$ parameter than the sample without such a defect. For the sample with cloud defect values of parameters $\Delta \mathrm{a}$ and $\Delta \mathrm{b}$ do not exceed 0.5 although change in the color is well observed. In this case parameter $\Delta \mathrm{L}$ (brightness parameter) explains the effect. $\Delta \mathrm{L}$ parameter gives some information about brightness in a given point and its fluctuations are caused by cloud defect that has an irregular distribution of grains in the resin.

The study on spectrophotometer for $8^{\circ}$ angle deviation from the perpendicular axis to the tested surface was finished with the $\Delta \mathrm{E}$ parameter not exceeding 1.0 for the sample without cloud defect.

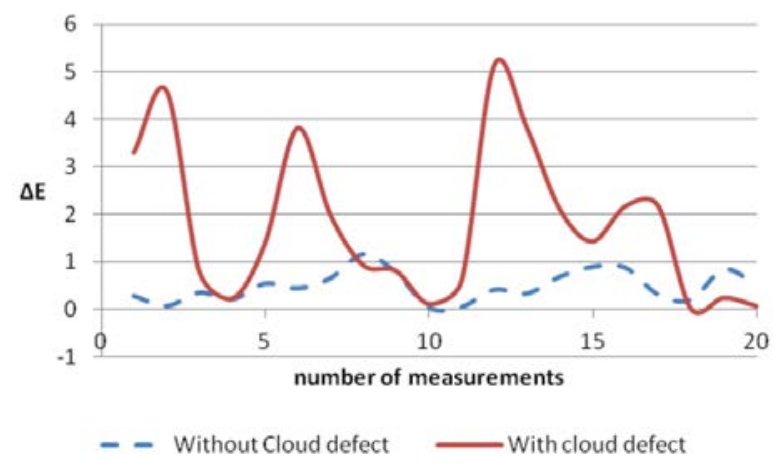

Fig. 4. Color difference for angle $25^{\circ}$.

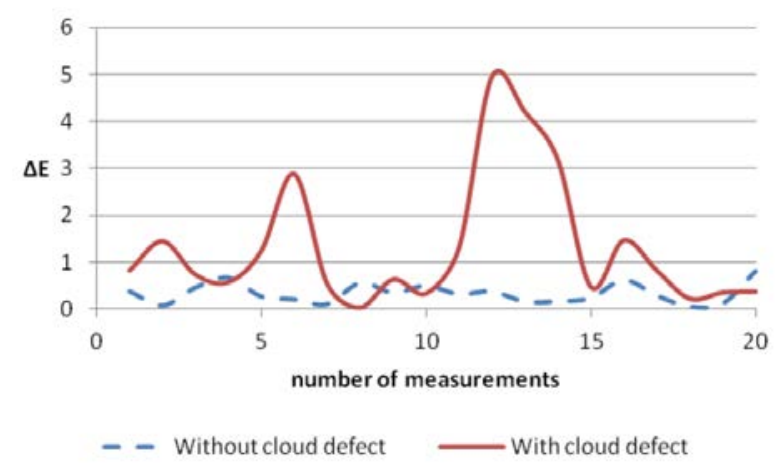

Fig. 5. Color difference for angle $45^{\circ}$.

\section{Summary and conclusions}

Low production costs due to an easy application, the same as for ordinary polyurethane varnish. Cross painting or application of a thin finishing layer is not required. Metallic effect is obtained without losing high gloss. It is comparable to the double layer systems. No cloud defect and entire coverage of primer is achieved when the paint is applied in two layers. Good resistance of finished product to aggressive environmental factors and good adhesion to steel.

Possibility to repair local damaged areas (scratches) without losing the surface appearance and metallic effect (BOKU゚VKa1 O., LiPTÁKOVÁ T., PALČEK P., CHALUPOVÁ M., TRŠKO L. 2013, BORKOWSKI S., KNOP K., 2013, ŠURINOVÁ Y., LESTYÁNSZKA ŠKŮRKOVÁ K., 2013, SZKLARZYK P., 2014, JAGUSIAKKOCIK M., 2014, KLIMECKA-TATAR D., 2014, ROMANKIEWICZ R., ROMANKIEWICZ F., 2014 HANUS P., KONEČNÝ M., 2014).

\section{References}

1. Hryniewicz T. 2004. Surface Technology and Coatings, Wydawnictwo Uczelniane Politechniki Koszalińskiej, Koszalin (Technologia powierzchni i powłok).

2. Collective Work 1983. Painting and Paint Coatings, ed. III, WNT, Warszawa (Praca zbiorowa: Powłoki malarsko-lakiernicze).

3. Service Manual 2/08. Painter Vademecum (Poradnik Serwisowy Vademecum lakiernik).

4. http://www.schlenk.com.

5. BOKU゚VKa1 O., LiptákOVÁ T., PALČEK P., CHALUPOVÁ M., TRŠKO L. 2013. The Influence of Wielded Joint Quality on Safety and Reliability in Operation Vol.1 No.1 Production Engineering Archives.

6. Borkowski S., KnOP K. 2013. Visual Control as a Key Factor in a Production Process of a Company from Automotive Branch Vol.1 No.1 Production Engineering Archives.

7. ŠURINOVÁ Y., LESTYÁNSZKA ŠKŮRKOVÁ K. 2013. Brief Review of German Standards for Quality Audits in Automotive Production Vol.1 No.1 Production Engineering Archives.

8. SZKLARZYK P. 2014. Visual Inspection as One of the Important Elements of the Quality Control Vol.2 No.1 Production Engineering Archives.

9. JAGUSIAK-KoCIK M. 2014. Ensuring Continuous Improvement Processes Through Standardization in the Automotive Company Vol.2 No.1 Production Engineering Archives.

10. KLIMECKA-TATAR D., 2014. Importance of Development Factors in Company Dealing with Cataphoresis Coating Method Vol.2 No.1 Production Engineering Archives.

11. ROMANKIEWICZ R., ROMANKIEWICZ F. 2014.The influence of Modification for Structure and Impact resistance of Silumin AlSi11 Vol.3 No.2 Production Engineering Archives.

12. HANUS P., KONEČNÝ M., 2014. Influence of the Welding Process on Martensitic High Strength Steel Vol.3 No.2 Production Engineering Archives. 